\title{
Prenatal Cocaine Exposure Increases Sensitivity to the Attentional Effects of the Dopamine D1 Agonist SKF81297
}

\author{
Lorna E. Bayer, ${ }^{1}$ Alison Brown, ${ }^{1}$ Charles F. Mactutus, ${ }^{3}$ Rose M. Booze, ${ }^{4}$ and Barbara J. Strupp ${ }^{1,2}$ \\ ${ }^{1}$ Department of Psychology and ${ }^{2}$ Division of Nutritional Sciences, Cornell University, Ithaca, New York 14853, and ${ }^{3}$ Division \\ of Pharmacology and Experimental Therapeutics, College of Pharmacy, Tobacco and Health Research Institute, Graduate \\ Center for Toxicology, and ${ }^{4}$ Department of Anatomy and Neurobiology, College of Medicine, University of Kentucky, \\ Lexington, Kentucky 40546
}

Sensitivity to the attentional effects of SKF81297, a selective full agonist at dopamine $D_{1}$ receptors, was assessed in adult rats exposed to cocaine prenatally (via intravenous injections) and controls. The task assessed the ability of the subjects to monitor an unpredictable light cue of either 300 or $700 \mathrm{msec}$ duration and to maintain performance when presented with olfactory distractors. SKF81297 decreased nose pokes before cue presentation and increased latencies and response biases (the tendency to respond to the same port used on the previous trial), suggesting an effect of SKF81297 on the dopamine (DA) systems responsible for response initiation and selection. The cocaine-exposed (COC) and control animals did not differ in sensitivity to the effects of SKF81297 on these measures. In contrast, the COC animals were significantly more sensitive than were controls to the impairing effect of SKF81297 on omission errors, a measure of sustained attention. This pattern of results provides evidence that prenatal cocaine exposure produces lasting changes in the DA system(s) subserving sustained attention but does not alter the DA system(s) underlying response selection and initiation. These findings also provide support for the role of $D_{1}$ receptor activation in attentional functioning.

Key words: prenatal cocaine; intravenous injection; catecholamine; dopamine; attention; response initiation; response selection
Concern about effects of prenatal cocaine exposure has grown in recent years. Although early media reports of gross neurological sequelae have proven primarily unfounded, recent controlled studies have revealed attentional dysfunction in exposed children that persists into school-age years (Richardson et al., 1996; Mayes et al., 1998; Dow-Edwards et al., 1999; Leech et al., 1999). Because maternal cocaine use in these studies generally occurred within the context of multiple risk factors, including polydrug abuse, it is important that animal model studies have demonstrated a clear causal link between prenatal cocaine exposure and attentional dysfunction (Romano and Harvey, 1996; Morgan et al., 1997; Wilkins et al., 1998a,b; Mactutus, 1999; Garavan et al., 2000). Elucidation of the neural bases of these deficits might allow amelioration or reversal of the dysfunction. This goal motivated the present study.

Altered dopamine (DA) activity, particularly in prefrontal and anterior cingulate cortices, is one mechanism that may underlie prenatal cocaine-induced attentional deficits. Moderate DA activity is critical for the optimal functioning of frontal cortical regions (for review, see Robbins et al., 1994; Arnsten, 1997), thought to subserve attentional functions impaired by cocaine exposure (for review, see Arnsten et al., 1994; Arnsten, 1997; Carter et al., 1997; Coull, 1998; Posner and Rothbart, 1998; Garavan et al., 2000). Prenatal cocaine exposure has been reported to disrupt CNS DA function (for review, see Mayes, 1999). However, definitive conclusions about the role of DA alterations in prenatal cocaineinduced attentional dysfunction cannot be drawn for several reasons. First, both the presence and direction of cocaine-induced alterations have been inconsistent across studies. Second, most

Received April 3, 2000; revised Aug. 25, 2000; accepted Sept. 13, 2000.

This work was supported by the National Institute on Drug Abuse Grants DA 07559 , DA 09160, and DA 1137 and the National Institute of Environmental Health Sciences Grants ES 06259 and ES 07457. We would like to thank Mareike Kuypers for excellent technical assistance, Dr. David Levitsky for apparatus development and support, Drs. Charles McCulloch and Ed Frongillo for expert statistical advice, and Donna Whiting for careful preparation of this manuscript.

Correspondence should be addressed to Dr. Barbara J. Strupp, Savage Hall, Cornell University, Ithaca, NY 14853. E-mail: bjs13@cornell.edu.

Copyright (C) 2000 Society for Neuroscience $0270-6474 / 00 / 208902-07 \$ 15.00 / 0$ studies administered cocaine via subcutaneous injections, which often cause necrotic skin lesions in cocaine-exposed dams (Bruckner et al., 1982). Therefore, the extent to which reported changes are caused by maternal stress rather than, or in addition to, cocaine exposure is unknown. A final limitation is the absence of direct links between DA systems and attentional dysfunction.

The present study was designed to test the hypothesis that altered activity at $\mathrm{D}_{1}$ receptors contributes to lasting attentional dysfunction in prenatal cocaine-exposed animals. Adult intravenous cocaine-exposed and control rats were administered SKF81297, a selective full $\mathrm{D}_{1}$ agonist, before being tested on an attentional task. Attentional effects of SKF81297 in control subjects were interpreted as supporting a role for $\mathrm{D}_{1}$ receptor mechanisms in attention. Altered sensitivity to the attentional effects of SKF81297 in cocaine-exposed subjects was considered indicative of enduring alterations in DA systems subserving attention.

Parts of this paper have been presented previously at the annual meeting of the Society for Neuroscience, Los Angeles, CA, November, 1998.

\section{MATERIALS AND METHODS}

Subjects. Nulliparous Long-Evans rats (Harlan Sprague Dawley, Indianapolis, IN), $\sim 11$ weeks old, were housed in American Association for Accreditation of Laboratory Animal Care-accredited animal facilities maintained at $21 \pm 2^{\circ} \mathrm{C}, 50 \pm 10 \%$ relative humidity, on a $12 / 12 \mathrm{hr}$ light/dark cycle. Food (Pro-Lab Rat, Mouse, Hamster Chow 3000) and water were available ad libitum. Subjects were randomly assigned either to receive a surgical catheterization procedure (described below) or to serve as unoperated surrogate controls. After surgery, subjects in the catheterization group were randomly assigned to receive either cocaine or saline (vehicle control). This research protocol was approved by the animal care review boards of the University of Kentucky and Cornell University.

Catheterization. Subjects in the catheterization group were surgically implanted with a sterile intravenous catheter [described in detail in Mactutus et al. (1994)]. Briefly, 1 week before mating, subjects were anesthetized with a mixture of ketamine hydrochloride $\left(100 \mathrm{mg} \cdot \mathrm{kg}^{-1} \cdot \mathrm{ml}^{-1}\right)$ and xylazine $\left(3.3 \mathrm{mg} \cdot \mathrm{kg}^{-1} \cdot \mathrm{ml}^{-1}\right)$ administered intraperitoneally. A sterile Intercath intravenous catheter (22 gauge; Becton Dickinson, Rutherford, NJ) with a Luer-lock injection cap (Medex) was cut to a length of $\sim 8 \mathrm{~cm}$ and implanted subcutaneously (SC). The distal end of the catheter was inserted into the jugular vein and threaded centrally. The proximal end of the catheter, including the injection cap, was left as a small SC pouch on the dorsal surface of the animal via which chronic intravenous injections were 
made. Catheter patency was maintained by daily flushing with $0.2 \mathrm{ml}$ of heparinized saline $(2.5 \%)$.

Mating. After recovery from surgery (4-8 d), the females were grouphoused $(n=3)$ with a male rat. Daily vaginal lavage of each female was performed to keep track of estrous cycles and to assist in defining conception. Conception [gestational day 0 GD0)] was confirmed by a spermpositive lavage.

Intravenous drug injection. Intravenous drug administration procedures were conducted as described in Mactutus et al. (1994). Briefly, all dams received daily intravenous saline injections $(1 \mathrm{ml} / \mathrm{kg})$ from conception until GD7. Dams in the saline subgroup $(n=8)$ continued to receive intravenous saline injections once per day from GD8 to GD14 and twice daily from GD15 to GD21. Dams in the cocaine subgroup $(n=8)$ received cocaine hydrochloride $\left(3.0 \mathrm{mg} \cdot \mathrm{ml}^{-1} \cdot \mathrm{kg}^{-1}\right.$, i.v.; Research Triangle Institute) once per day from GD8 to GD14 and twice daily from GD15 to GD21. The drug was dissolved immediately before injection.

This intravenous injection procedure mimics the rapidly peaking pharmacokinetic profile after inhalation or intravenous injection of cocaine in humans. The $3.0 \mathrm{mg} / \mathrm{kg}$ dose produces peak arterial plasma levels that are similar to those reported for humans administered $32 \mathrm{mg}$ of cocaine intravenously (Evans et al., 1996; Booze et al., 1997). Under experimental conditions, this dose is self-administered by "users" multiple times in a 2.5 hr session (Fischman and Schuster, 1982) and thus represents a low or recreational dose, highly relevant to the clinical situation being modeled. This regimen (route, dose, and rate) produces no evidence of overt maternal or fetal toxicity, no maternal seizure activity, no effect on maternal weight, and no effect on offspring growth or mortality (Mactutus et al., 1994; Mactutus, 1999). Furthermore, this intravenous injection procedure does not reduce the food intake of dams even when a cocaine dose as high as $6 \mathrm{mg} / \mathrm{kg}$ is used (Robinson et al., 1994), precluding the need for pair-fed controls.

Offspring treatment. All cocaine- and saline-exposed offspring used during this study were generated simultaneously. Within $24 \mathrm{hr}$ of birth, pups were weighed, culled to four males and four females per litter (when possible), and fostered to a surrogate dam who had given birth within the preceding $24 \mathrm{hr}$. Fostering was conducted for both cocaine- (COC) and saline-exposed (SAL) offspring to limit the effects of the maternal drug treatment to the prenatal period; i.e., potential effects of gestational cocaine treatment on maternal behavior were removed as a source of offspring differences.

On postnatal day 21 (PND21), pups were weaned and ear-punched for identification. Within $10 \mathrm{~d}$ of weaning, one male and one female offspring from each litter were shipped under environmentally controlled conditions from Lexington, KY, to Ithaca, NY (Cornell University). After arrival, subjects were housed in same-sex pairs on a reversed dark/light cycle and allowed to acclimate to the new environment for $2-3$ weeks. Training and behavioral testing began for all animals on PND48. All personnel handling and testing the animals were blind to their treatment conditions. Offspring tested in the current study included 15 COC (eight male and seven female) and 15 SAL (seven male and eight female) animals. The animals were $\sim 160 \mathrm{~d}$ of age at the beginning of the present study.

Behavioral testing: apparatus. Testing was conducted in 10 automated Plexiglas chambers enclosed in sound-attenuating wooden boxes, each operated by an IBM personal computer XT. Each chamber consisted of a square waiting area (26.5 by 25 by $30 \mathrm{~cm}$ ), adjacent to a testing alcove containing three funnel-shaped ports. A light-emitting diode (LED) was mounted above each port. A thin metal door, raised at the initiation of each trial, separated these two compartments. The left and right ports were $8 \mathrm{~cm}$ apart, each at an $\sim 45^{\circ}$ angle relative to the center port. Each port was connected by tubing to three bottles containing liquid odorants, attached to a board placed outside of the wooden enclosure. Solenoid valves controlled the presentation of compressed air, pumped through a specific odorant and through a specific port. The airflow rate was $1.0 \mathrm{l} / \mathrm{min}$, and the air in the chamber was cleared via small centrifugal fans mounted on the outside of the chambers, at a rate of four complete exchanges per minute. A set of infrared phototransistors and a light source monitored the entrance to the alcove and each port. A $1 \mathrm{sec}$ nose poke into one of the three ports indicated a response. Correct responses were reinforced with a $45 \mathrm{mg}$ food pellet (Noyes, Lancaster, NH) delivered into the alcove from a pellet dispenser (Lafayette Instrument Company, Lafayette, IN).

Training procedure. As part of a previous experiment (Morgan et al., 1997), subjects were first trained to make a $1 \mathrm{sec}$ nose poke into a port to receive a reward pellet. Subjects were then trained on a series of consecutive attention tasks: (1) a three-choice visual discrimination in which subjects were rewarded for responding to the port under the illuminated LED, (2) a series of vigilance tasks in which the delay before cue onset varied as did the duration of the light cue, and (3) a variant of the distraction task described below. Subjects were maintained on a restricted feeding schedule ( $\sim 18 \mathrm{gm} / \mathrm{d}$ for females; $21 \mathrm{gm} / \mathrm{d}$ for males) to motivate the animals to perform the task.

Distraction task. Before initiation of the SKF81297 challenge study, subjects received an additional $12 \mathrm{~d}$ of testing on the distraction task to achieve a stable baseline performance level for each rat. In this task, the opening of the alcove door signaled the onset of each trial. After the subject entered the testing alcove, one of the three LEDs was briefly illuminated (the discriminative stimulus). A $1 \mathrm{sec}$ nose poke into the port under the illuminated light was deemed correct and resulted in delivery of a $45 \mathrm{mg}$ Noyes pellet. Several parameters were randomly varied across the trials in each session: (1) the prestimulus delay ( 2 or $3 \mathrm{sec}$ after alcove entry), (2) duration of the light cue (300 or $700 \mathrm{msec}$ ), and (3) presentation of an olfactory distractor. On one-third of the trials in each session, one of nine different odors was delivered randomly through one of the ports (i.e., it could emanate from the correct or incorrect ports), either 1 or $2 \mathrm{sec}$ before visual cue onset. No odors were presented on the remaining one-third of the daily trials (nondistraction trials). The prestimulus delay, cue duration, cue location, and distraction condition for each trial were selected pseudorandomly, balanced for each session. A correct response (defined above) resulted in delivery of a food pellet and ended the trial, signaled by the closing of the alcove door. Incorrect responses included the following: (1) a 1 sec nose poke into any port before the light cue onset (premature response), (2) a $1 \mathrm{sec}$ nose poke into an incorrect port after cue presentation (an inaccurate response), and (3) entering the alcove but failing to respond within $15 \mathrm{sec}$ of trial onset (an omission error). Each of these incorrect responses also terminated the trial, but with no reinforcement. If the animal failed to enter the alcove within $30 \mathrm{sec}$ after the door was raised, the alcove door closed, and a nontrial was recorded. An intertrial interval of $5 \mathrm{sec}$ was imposed between successive trials. A variant of this task had revealed enduring effects of prenatal cocaine exposure on selective attention in this cohort of animals previously (Morgan et al., 1997).

Response types. Means for percentage correct, alcove and response latencies, and nontrials were calculated for each session. In addition, means for the following error types were calculated: premature responses, inaccurate responses, and omission errors. Also analyzed were (1) response bias, the tendency to respond to the same port used on the previous trial, and (2) prepokes, defined as nose pokes of $<1 \mathrm{sec}$ that did not constitute a choice.

SKF81297 challenge study. Daily sessions consisted of 100 trials or 60 min, whichever came first. Each animal received three test sessions per week (Monday, Wednesday, and Friday). All 30 subjects were tested on each testing day, using three sequential $1 \mathrm{hr}$ shifts $(12: 30,1: 30$, and 2:30 P.M.), each containing 10 subjects. Prenatal treatment was balanced across the shift and testing chamber $(n=10)$. SKF81297 $(0.03,0.1$, and 0.3 $\mathrm{mg} / \mathrm{kg}$; Research Biochemicals, Natick, MA) or vehicle control was administered subcutaneously $15 \mathrm{~min}$ before testing. SC administration was used to minimize injection stress. The time course of the effects of SKF81297 on behavior following this route of administration has been well established (Lublin et al., 1992, 1993, 1994; Gerlach and Hansen, 1993). Each subject received each of the four doses five times, with dose order determined by a Latin square design. Successive injection days were separated by a minimum of $48 \mathrm{hr}$ to allow drug clearance.

Statistical analysis. Data were analyzed using the SAS version 6.11 PROC MIXED mixed models ANOVA procedure that uses maximum likelihood estimation to account appropriately for the correlated structure within repeated measures designs. To normalize the distributions, an arcsine square-root transformation was applied to the percentage correct, percentage premature errors, percentage omission errors, and percentage accuracy data. The percentage correct was analyzed as a function of prenatal treatment, sex, SKF81297 dose, prestimulus delay, cue duration, distraction condition [no distractor, distractor 1 sec before cue ("- 1 " distractor), or distractor $2 \mathrm{sec}$ before cue ("-2" distractor)], and the relevant interactions of these variables. Prenatal treatment and sex were included as between-subjects variables, the SKF81297 dose was included as a within-subject variable, and delay, duration, and distraction were included as within-subject, within-session variables. Similar analyses were conducted on the following specific error types: percentage omission errors, percentage accuracy errors, and percentage premature responses.

Similar analyses were conducted on prepokes. Two types of prepokes were distinguished: those prepokes that occurred before the light cue (early) and those that occurred after the cue (late). The former were considered indicative of impulsivity, whereas the latter were thought to reflect decision-making processes.

Effects on motivation level were assessed by analyses of nontrials and the alcove latency. To normalize the distribution, alcove latencies were natural $\log$ transformed before analysis and then analyzed as a function of prenatal treatment, sex, SKF81297 dose, correctness on the previous trial, and the relevant interactions of these variables. Nontrials were analyzed as a function of prenatal treatment, sex, SKF81297 dose, and the relevant interactions of these variables.

Similar analyses were conducted on the mean response latency. Separate analyses were conducted on those response latencies that occurred on correct trials versus those that occurred on incorrect trials. The former were considered to reflect the information-processing speed, whereas the latter provide insight into the types of errors committed.

Response bias was analyzed as a function of prenatal treatment, sex, SKF81297 dose, prestimulus delay, light cue duration, distraction condition, correctness of the previous trial, and the relevant interactions of these variables.

\section{RESULTS}

For all figures of the percentage correct and percentage error-type data, least squares means (and associated SEs) of transformed data 


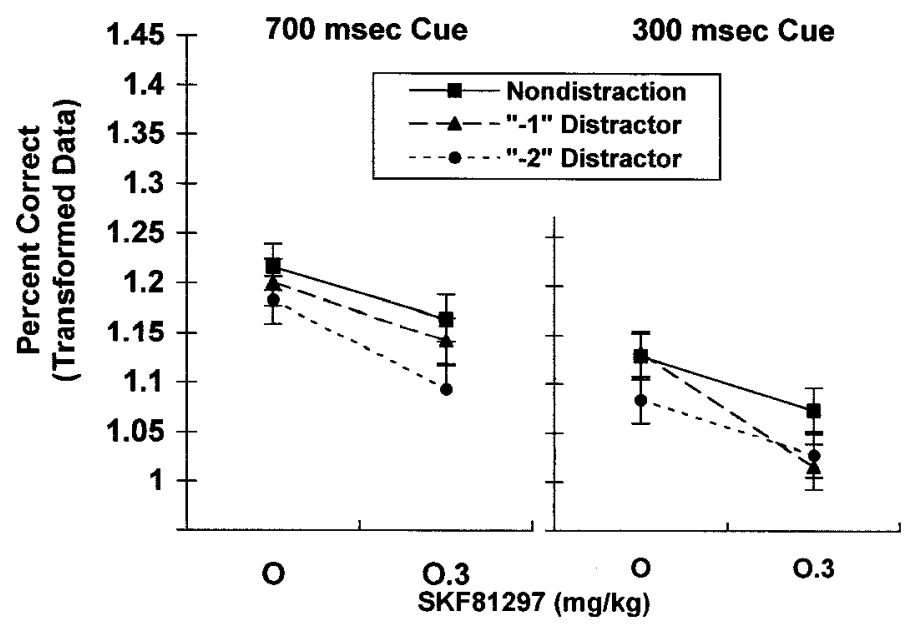

Figure 1. Effect of SKF81297 on the overall percentage correct. The highest dose of SKF81297 decreased the percentage correct (high dose vs vehicle, $p=0.0001$ ). To simplify the figure, only the vehicle and $0.3 \mathrm{mg} / \mathrm{kg}$ dose are included, because this highest dose is the only one at which a significant drug effect was seen. The magnitude of this impairment was greatest under the $300 \mathrm{msec}$ cue and the "-1" distractor condition (SKF by cue duration by distraction, $p=0.0249$ ). See Results for details (1.01 and 1.24 on the $y$-axis correspond to 72 and $89 \%$, respectively).

are presented rather than raw geometric means because they more accurately reflect the results of the statistical analyses.

\section{Maternal and/or litter effects}

Prenatal cocaine treatment did not alter maternal weight gain during gestation, measured on GD0, GD8, GD15, and GD21 $\left[F_{(1,16)}=0.00 ; p \leq 0.98\right]$; gestation length $\left[F_{(1,15)}=0.01 ; p \leq 0.93\right]$; pup birth weight $\left[F_{(1,16)}=0.44 ; p \leq 0.52\right]$; litter sex ratio $\left[F_{(1,14)}=\right.$ $0.66 ; p \leq 0.43]$, or litter size $\left[F_{(1,16)}=0.01 ; p \leq 0.92\right]$.

\section{Percentage correct}

The percentage correct for a given session was calculated as the percentage of trials in the session on which the correct response was made within $10 \mathrm{sec}$ of trial onset. The percentage correct was lowest under conditions of greatest attentional demand: $300 \mathrm{msec}$ light cue condition [duration, $F_{(1,1285)}=300.81 ; p=0.0001$ ], trials with distractors [distraction condition, $F_{(2,1285)}=24.78 ; p=$ 0.0001 ], and $3 \mathrm{sec}$ prestimulus delay [delay, $F_{(1,1285)}=14.69 ; p=$ $0.0001]$. Prenatal cocaine exposure did not alter the overall percentage correct $\left[F_{(1,27)}=0.00 ; p=0.9916\right]$, nor was there a prenatal treatment by SKF81297 interaction on this measure $\left[F_{(3,81)}=0.86 ; p=0.4634\right]$. SKF81297 decreased the percentage correct $\left[F_{(3,81)}=24.58 ; p=0.0001\right]$, specifically at the highest dose (vehicle vs high dose, $p=0.0001$ ); the two lower doses of SKF81297 did not significantly alter this response type. As seen in Figure 1, the magnitude of this drug-induced impairment was greatest on trials in which a distractor was presented $1 \mathrm{sec}$ before presentation of the shorter cue [SKF by cue duration by distraction, $\left.F_{(6,1285)}=2.42 ; p=0.0249\right]$.

\section{Inaccurate responses}

Inaccurate responses were calculated as the percentage of trials in the session in which an incorrect port was chosen after the light cue offset, within $10 \mathrm{sec}$ of trial onset. The rate of inaccurate responses was highest under conditions of greatest attentional demand: trials with the $300 \mathrm{msec}$ light cue [duration, $F_{(1,1294)}=347.24 ; p=$ 0.0001 ] and trials with distractors [distraction condition, $F_{(2,1294)}=$ $13.90 ; p=0.0001]$. This measure was not affected by prenatal cocaine exposure $\left[F_{(1,26)}=0.08 ; p=0.7851\right]$, SKF81297 dose $\left[F_{(3,81)}=0.65 ; p=0.5821\right]$, or the interaction of these variables $\left[F_{(3,81)}=0.46 ; p=0.7129\right]$.

\section{Premature responses}

Premature responses were calculated as the percentage of trials in the session on which the subject made a response before light cue

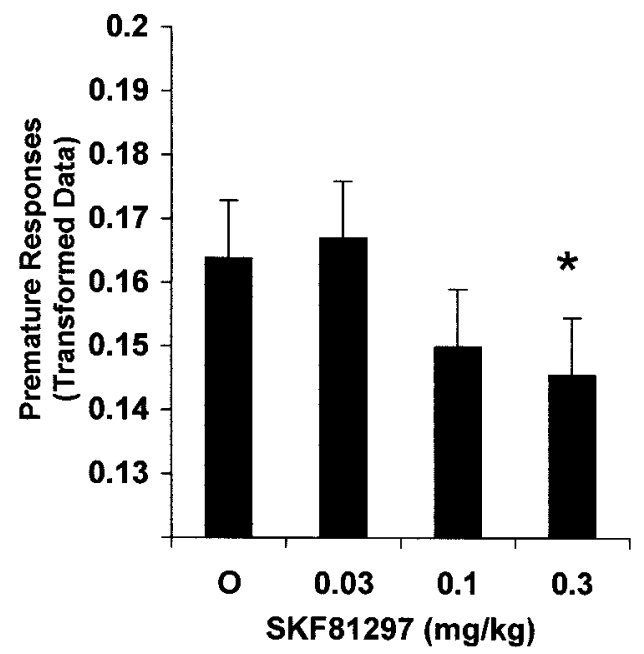

Figure 2. Effect of SKF81297 on premature responses. SKF81297 decreased the overall premature response rate $(p=0.0228)$, specifically at the highest dose (vehicle vs high dose, $\left.{ }^{*} p \leq 0.0255\right)$. See Results for details $(0.14$ and 0.17 on the $y$-axis correspond to 1.9 and $2.9 \%$, respectively).

presentation. To reduce the proportion of zeros in the data set, it was necessary to average data across cue duration and the timing of distractor onset (" -1 " vs " -2 " distractor conditions).

Prenatal cocaine treatment did not alter the premature response rate $\left[F_{(1,27)}=0.10 ; p=0.7498\right]$, nor was there an interaction of prenatal treatment and SKF81297 dose $\left[F_{(3,84)}=1.41 ; p=0.2450\right]$. There was a significant effect of SKF81297 on the premature response rate $\left[F_{(3,84)}=3.350 .0228\right]$, reflecting the fact that the highest dose of SKF81297 significantly decreased premature responses (vehicle vs high dose, $p=0.0255$ ), a tendency also seen at the medium dose (vehicle vs medium dose, $p=0.0894$ ) (see Fig. 2). In addition, females made more premature responses than did males $\left[F_{(1,27)}=6.36 ; p=0.0179\right]$.

\section{Omission errors}

The percentage of omission errors was calculated as the percentage of trials in the session on which the subject entered the testing alcove but failed to respond within $15 \mathrm{sec}$ of trial onset. These errors were considered indicative of lapses of attention. To reduce the proportion of zeros on this measure in the data set, it was necessary to average data across the prestimulus delay and timing of distractor onset ("-1" vs " -2 " distractor conditions). The rate of omission errors was higher on trials with the $300 \mathrm{msec}$ cue than on those with the $700 \mathrm{msec}$ cue [duration, $F_{(1,348)}=49.32 ; p=$ $0.0001]$, consistent with the interpretation that omission errors reflect lapses in attention.

There was no main effect of prenatal cocaine treatment on the omission error rate $\left[F_{(1,26)}=0.36 ; p=0.5534\right]$. In contrast, SKF81297 increased omission errors [SKF, $F_{(3,81)}=57.49 ; p=$ $0.0001]$, specifically at the two highest doses (vehicle vs medium dose, $p=0.0456$; vehicle vs high dose, $p=0.0001)$. In addition, COC rats were more sensitive than were controls to SKF81297's impairing effect on this measure [COC by SKF, $F_{(3,81)}=2.75 ; p=$ 0.0481], exhibiting impairment at a lower dose of SKF81297 than seen in SAL rats. COC rats were impaired by the $0.1 \mathrm{mg} / \mathrm{kg}$ dose of SKF81297 (vehicle vs $0.1 \mathrm{mg} / \mathrm{kg}$ dose for COC rats, $p=0.0035$ ), whereas SAL rats were not impaired by this dose (vehicle vs 0.1 $\mathrm{mg} / \mathrm{kg}$ dose for SAL rats, $p=0.8889$ ). There was a tendency for the two groups to differ in the omission error rate at this dose, but the contrast did not achieve statistical significance $(p \leq 0.1116)$. The $0.3 \mathrm{mg} / \mathrm{kg}$ dose of SKF81297 impaired both the COC (vehicle vs $0.3 \mathrm{mg} / \mathrm{kg}$ dose for COC rats, $p=0.0001)$ and the SAL groups (vehicle vs $0.3 \mathrm{mg} / \mathrm{kg}$ dose for SAL rats, $p=0.0001$ ), and the two groups did not differ in the omission error rate at this dose $(p \leq$ $0.4144)$. The groups did not differ in the vehicle condition $(p=$ 0.9981; see Fig. 3). 


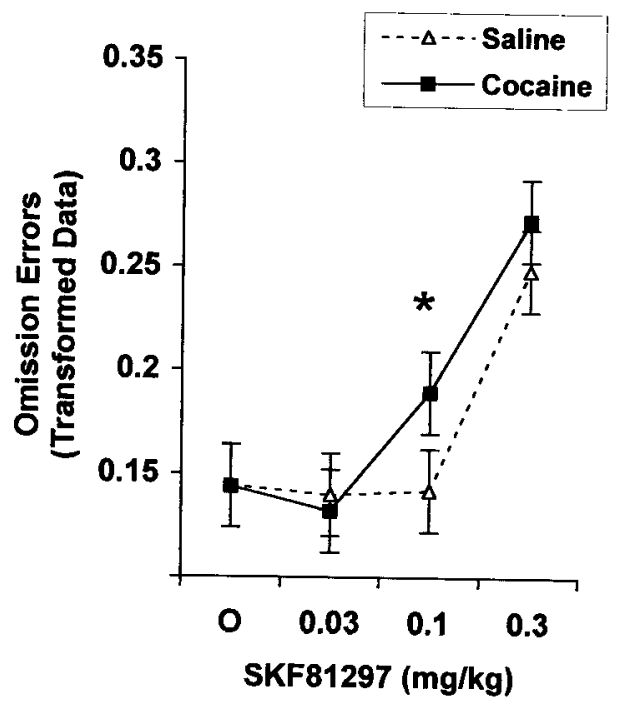

Figure 3. COC rats showed increased sensitivity to SKF81297's impairing effect on omission errors. COC rats were more sensitive than were SAL rats to SKF81297's effect on omission errors (COC by SKF, $p=0.0481$ ), showing impairment at a lower dose of SKF81297 than seen with SAL rats (vehicle vs $0.1 \mathrm{mg} / \mathrm{kg}$ dose for COC rats, ${ }^{*} p=0.0035$; vehicle vs $0.1 \mathrm{mg} / \mathrm{kg}$ dose for SAL rats, $p=0.8889)$. See Results for details $(0.13$ and 0.27 on the $y$-axis correspond to 1.7 and $7.1 \%$, respectively).

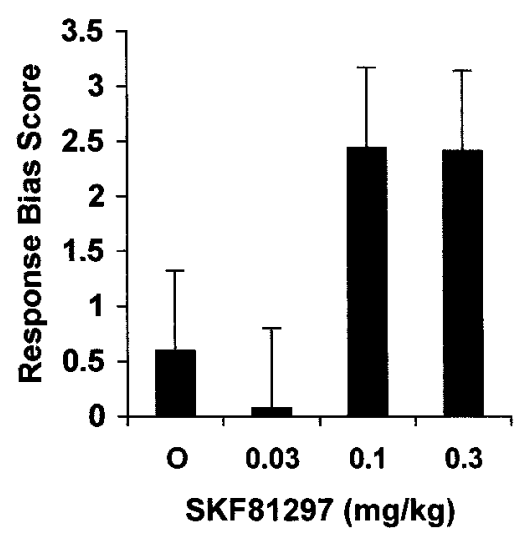

Figure 4. Effect of SKF81297 on response bias. Response bias was significantly affected by the SKF81297 dose $(p=0.0345)$, an effect that was driven, in part, by a borderline increase in bias produced by the two highest doses relative to the vehicle dose (vehicle vs medium dose, $p \leq 0.0703$; vehicle vs high dose; $p \leq 0.0763$ ). See Results for details.

\section{Response bias}

Response bias, the tendency to respond to the same port used on the previous trial, was also analyzed. The dependent measure was the percentage of trials in a session on which the rat responded to the same port used in the previous trial, corrected for the baseline response bias score for that session. This correction was needed because (1) the magnitude of the response bias that would be expected by chance is slightly affected by the pattern of correct ports in a given session and (2) the raw response bias score is correlated with performance level because of the constraint imposed on the number of times that a given port is correct on successive trials.

There was a significant effect of SKF81297 dose on response bias $\left[F_{(3,2679)}=2.88 ; p=0.0345\right]$, an effect apparently driven by an increased bias seen at the two highest doses relative to the vehicle (vehicle vs medium dose, $p=0.0703$; vehicle vs high dose, $p=$ 0.0763 ) (see Fig. 4). In contrast, prenatal cocaine exposure did not affect response bias $\left[F_{(1,26)}=1.33 ; p=0.2586\right]$, nor did this measure exhibit a significant prenatal treatment by SKF81297 interaction $\left[F_{(3,2679)}=1.99 ; p=0.1138\right]$.

\section{Prepokes}

Also analyzed were prepokes, nose pokes of $<1 \mathrm{sec}$ that did not constitute a choice. Two categories of prepokes were analyzed: early prepokes, those occurring before illumination of the light cue, and late prepokes, those occurring after cue onset. The former were considered indicative of impulsivity, whereas the latter were considered to reflect decision-making processes. Data for prepokes were averaged across cue duration, delay, and the timing of distractor onset ("- 1 " vs " -2 " distractor conditions) to reduce the proportion of zero values in the data set.

Prenatal cocaine exposure did not alter the incidence of early prepokes $\left[F_{(1,26)}=0.04 ; p=0.8394\right]$, nor was there a prenatal treatment by SKF81297 interaction on this measure $\left[F_{(3,79)}=0.42\right.$; $p=0.7390]$. In contrast, SKF81297 markedly decreased the rate of this type of response $\left[F_{(3,79)}=11.47 ; p=0.0001\right]$, specifically at the two higher doses (vehicle vs medium dose, $p=0.035$; vehicle vs high dose, $p=0.0001$ )

SKF81297 increased the rate of late prepokes $\left[F_{(3,549)}=33.83\right.$; $p=0.0001$ ], specifically at the two higher doses (vehicle vs medium dose, $p=0.0088$; vehicle vs high dose, $p=0.0001)$. However, prenatal cocaine exposure did not alter this measure $\left[F_{(1,26)}=0.26\right.$; $p=0.6158]$, nor was there an interaction of prenatal treatment and SKF81297 dose $\left[F_{(3,549)}=1.44 ; p=0.2304\right]$.

\section{Response latencies}

Prenatal cocaine exposure did not alter the response latency on correct trials $\left[F_{(1,26)}=0.21 ; p=0.6541\right]$, nor was there an interaction of prenatal treatment and SKF81297 dose on this measure $\left[F_{(3,78)}=1.36 ; p=0.2603\right]$. SKF81297 increased the average response latency on correct trials $\left[F_{(3,78)}=8.54 ; p=0.0001\right]$, an effect limited to the highest dose (vehicle vs high dose, $p=0.0001$ ).

Prenatal cocaine exposure did not alter the response latency on incorrect trials $\left[F_{(1,26)}=0.62 ; p=0.4398\right]$, nor was there an interaction of prenatal treatment and SKF81297 dose on this measure $\left[F_{(3,78)}=0.36 ; p=0.7797\right]$. SKF81297 increased the average response latency on incorrect trials $\left[F_{(3,73)}=9.97 ; p=\right.$ $0.0001]$. This increase in response latency was observed at each of the three SKF81297 doses relative to controls: low $(p=0.0134)$, medium ( $p=0.0002)$, and high $(p=0.0001)$.

\section{Alcove latency}

SKF81297 increased mean alcove latency $\left[F_{(3,108)}=16.34 ; p=\right.$ $0.0001]$, specifically at the highest dose (vehicle vs high dose, $p=$ $0.0001)$. However, prenatal cocaine exposure did not alter mean alcove latency $\left[F_{(1,26)}=0.03 ; p=0.8689\right]$, nor was there an interaction of prenatal treatment and SKF81297 dose on this measure [COC by SKF, $F_{(3,108)}=0.11 ; p=0.9554$ ].

\section{Nontrials}

Prenatal cocaine exposure did not alter the nontrial rate $\left[F_{(1,26)}=\right.$ $0.16 ; p=0.6944]$. In addition, there was no effect of SKF81297 on this measure $\left[F_{(3,485)}=1.24 ; p=0.2957\right]$, indicating that neither the drug nor the prenatal treatment affected the motivation level on this task. Finally, the interaction of prenatal treatment and SKF81297 was not significant $\left[F_{(3,485)}=0.16 ; p=0.9216\right]$.

\section{DISCUSSION}

The results of the current study have important implications for the role of DA alterations in the attentional dysfunction produced by prenatal cocaine exposure and for the role of $\mathrm{D}_{1} \mathrm{DA}$ activity in normal behavior and cognition.

SKF81297 affected numerous dependent measures in this attention task. The drug decreased early prepokes and premature responses and increased latencies and response bias, a pattern that reflects an effect of SKF81297 on DA systems responsible for response initiation and selection (discussed below). The effects of SKF81297 on these variables did not differ between treatment groups, suggesting that the DA systems responsible for these functions are unaltered by prenatal cocaine exposure.

In addition, the analysis of omission errors revealed a significant 
interaction of SKF81297 and prenatal treatment, the critical finding considered indicative of an enduring effect of prenatal cocaine exposure on DA systems. The finding that the statistical interaction of SKF81297 and prenatal treatment was only seen for omission errors, not for measures that appear to tap DA systems subserving response initiation and selection, suggests that the omission error effect was mediated by DA activity in a brain region(s) different from that producing these former effects. One interpretation that fits the pattern of findings is that this differential effect on omission errors reflects a cocaine-induced alteration in mesocortical DA projections underlying attention (for review, see Pennington, 1994; Robbins et al., 1994; Williams and Goldman-Rakic, 1995; Arnsten, 1997), whereas the drug effects on response selection and initiation are likely mediated by effects on striatal DA neurons (Brown and Robbins, 1989a,b, 1991; Carli et al., 1989; Montgomery and Buchholz, 1991; Kermadi and Boussaoud, 1995; Robbins, 1997).

Thus, the pattern of results, overall, suggests that the differential effect of SKF81297 on omission errors in the present study reflects a lasting effect of prenatal cocaine exposure on the DA modulation of attention. However, it should be noted that because this differential sensitivity to SKF81297 was seen on a measure tapping sustained attention, but not on measures that tap selective attention and distractibility (e.g., premature responses and inaccurate responses), these inferred DA changes are not likely to have relevance for the selective attention dysfunction that has been reported for cocaine-exposed subjects (Romano and Harvey, 1996; Gabriel and Taylor, 1998; Wilkens et al., 1998a,b; Garavan et al., 2000). However, they are relevant for the sustained attention deficits that have also been reported in studies of cocaine-exposed children (Richardson et al., 1996) and animal models (Morgan et al., 1997). For example, Richardson et al. (1996) reported that prenatal cocaine-exposed children committed more omission errors than did controls on the continuous performance test, a visual attention task. Omission errors in this task, as in the present study, are indicative of lapses in attention. Attentional lapses also seem to contribute to the impaired performance of COC animals in a sustained attention task in rats (Morgan et al., 1997). By identifying the neural system likely to underlie this type of attentional dysfunction in cocaine-exposed subjects, the present results may aid in identifying possible candidates for therapeutic intervention.

It may be noted that, in the current study, attentional effects of prenatal cocaine exposure were only seen under the influence of SKF81297, i.e., not in the nondrug state. However, previous findings from this same cohort of animals revealed that the COC animals were significantly impaired relative to controls in terms of both sustained and selective attention. Notably the impairment in selective attention was observed in a distraction task that is almost identical to that used in the present study (Morgan et al., 1997). Another finding from this previous study may explain why attentional impairment was not seen in the COC animals in the present study. Specifically, the magnitude of the selective attention impairment decreased with increasing experience on the task. This finding suggests that the $\mathrm{COC}$ animals, despite their attentional impairment, were eventually able to filter out these distracting cues with extensive training with the same set of distracting cues. There is every reason to believe, however, that the greater distractibility of these COC animals would again become apparent if novel distractors were presented or the animals were tested in a novel task.

The pattern of drug effects on omission errors suggests an increased sensitivity to SKF81297 in the cocaine-exposed animals. Although the basis of this effect is not known, the most likely underlying mechanism is a lasting effect of prenatal cocaine exposure on DA release. The available evidence from studies using similar intravenous cocaine exposure regimens (cocaine dose and route of administration) supports the hypothesis that prenatal cocaine exposure increases the amount of DA released in response to a stressor or a pharmacological challenge but does not alter basal DA levels or release. Prenatal cocaine-exposed rabbits exhibited enhanced release of DA in the caudate nucleus after an amphet- amine challenge, relative to controls, whereas basal DA levels were unaffected (Du et al., 1999). Similarly, cocaine-exposed rats exhibited increased DA metabolic activity (as measured by the DOPAC/DA ratio) relative to controls in ventral prefrontal cortex (PFC) after a foot shock, whereas basal DA metabolic activity levels were unaffected (Elsworth et al., 1999) (J. D. Elsworth, personal communication). Further support that prenatal cocaine exposure does not affect basal DA activity is provided by additional findings from the rabbit model showing no change in basal tyrosine hydroxylase immunoreactivity in cingulate cortex (Wang et al., 1996) or in in vitro DA levels in cingulate cortex, frontal cortex, or striatum (Wang et al., 1995a). Finally, in an in vitro slice system, prenatal cocaine enhanced responsiveness of the presynaptic DA autoreceptor in cingulate and frontal cortices but not in striatum (Wang et al., 1995a). Enhanced autoreceptor sensitivity may represent a compensatory response to this putative stress-induced increase in DA release (or vice versa), because these receptors provide a negative-feedback system. In view of recent data suggesting that the testing on PFC-dependent tasks increases extracellular DA in PFC (Watanabe et al., 1997), it is possible that the COC animals in the present study experienced excessive DA activity in PFC when tested on our attentional tasks, contributing to the attentional impairment observed in previous tasks (Morgan et al., 1997) discussed above.

An alternate hypothesis is that the increased sensitivity of the COC animals to SKF81297 reflects an increased number or efficacy of $\mathrm{D}_{1}$ receptors. However, this mechanism is unlikely on the basis of previous findings that prenatal exposure to cocaine (1) did not affect $\mathrm{D}_{1}$ mRNAs (DeBartolomeis et al., 1994) or receptor binding in the striatum, nucleus accumbens, or ventral tegmental area (Leslie et al., 1994) and (2) resulted in decreased $\mathrm{D}_{1}$ receptor G-protein coupling in the striatum, anterior cingulate, and frontal cortex (Wang et al., 1995b; Friedman et al., 1996; Levitt et al., 1997). In fact, this latter finding of reduced $D_{1}$ coupling in intravenous cocaine-exposed rabbits appears inconsistent with the present findings. Future research is needed to determine whether reduced $D_{1}$ receptor G-protein coupling is also seen following the particular cocaine exposure regimen used in the present study (route, dose, and developmental period) and, if so, how this effect can be reconciled with the present findings.

In view of the inconsistent findings concerning prenatal cocaine effects on dopamine function, additional studies are needed to clarify how the increased sensitivity to SKF81297's attentional effects arises at the receptor and/or intracellular level. DA interactions with other neurotransmitter systems may well be involved, consistent with the suggestion of another study from our laboratory that prenatal cocaine exposure increases sensitivity to the behavioral effects of $\alpha_{2}$ adrenergic receptor-modulated DA release (Bayer et al., 1996).

The finding that $\mathrm{COC}$ animals are more sensitive than controls to the attentional effects of SKF81297 has functional implications. Because stress increases endogenous DA activity (Thierry et al., 1976; Horger and Roth, 1996), individuals exposed to cocaine in utero may be more vulnerable to the adverse effects of stress on cognition. This hypothesis is consistent with the finding that cocaine-exposed rats showed increased sensitivity to the impairing effects of the pharmacological stressor FG-7142 on a PFCdependent cognitive task (Murphy et al., 1995). This hypothesized effect of prenatal cocaine exposure on stress-induced attentional impairment is also consistent with reports of an altered behavioral and neurochemical response to stress in cocaine-exposed animals (Bilitzke and Church, 1992; Goldstein et al., 1993; Wood et al., 1993, 1994, 1995; Molina et al., 1994; Johns and Noonan, 1995; Church and Tilak, 1996; Goodwin et al., 1997; Elsworth et al., 1999) (J. D. Elsworth, personal communication).

\section{Implications for the cognitive roles of dopaminergic systems and $D_{1}$ receptors}

In addition to delineating the mechanism for prenatal cocaineinduced attentional dysfunction, several observed effects of 
SKF81297 clarify the role of $\mathrm{D}_{1}$ DA activity in specific cognitive functions. The observed pattern of results supports the hypothesized role of DA in response initiation and selection. SKF81297 decreased premature responses and early prepokes and increased response and alcove latencies, suggesting that the drug altered response initiation, perhaps via activation of $D_{1}$ receptors in the striatum. This finding corresponds with the hypothesized role of the mesostriatal DA system in behavioral activation and response preparation (Carli et al., 1985, 1989; Pullman et al., 1988; Brown and Robbins, 1989a,b, 1991; for review, see Robbins, 1997). SKF81297 also increased response bias, suggesting that the drug altered response selection. This finding is consistent with the theory that striatal DA neurons participate in programming target acquisition and the selection of responses from the repertoire of available responses (Brown and Robbins, 1989a,b, 1991; Carli et al., 1989; Montgomery and Buchholz, 1991; Kermadi and Boussaoud, 1995).

The attentional impairment produced by SKF81297, manifested as an increase in omission errors, provides new evidence of the hypothesized role of mesocortical DA in attention. This finding corroborates the existing evidence that moderate DA activity in prefrontal cortex is commensurate with optimal functioning of this region, whereas both suboptimal and supraoptimal DA activity impairs PFC-dependent functions such as working memory (Murphy et al., 1996; Arnsten, 1997; Zahrt et al., 1997). Granon et al. (2000) proposed that an inverted U-shaped relationship also exists between PFC DA activity and attention and provided support for the ascending portion of the curve (i.e., attentional enhancement), using PFC microinf usions of the partial $\mathrm{D}_{1}$ agonist SKF38393. The present findings, using the full $\mathrm{D}_{1}$ agonist SKF81297, extend these data by providing evidence of the downward side of the inverted U-shaped curve (i.e., attentional impairment). Finally, the present study, along with the report by Granon et al. (2000), provides important new evidence of an attentional role for DA activity specifically at the $\mathrm{D}_{1}$ receptor subtype. Although previous investigations have suggested that the $\mathrm{D}_{1}$ receptor subtype is most essential for PFC-dependent cognitive functions (Sawaguchi and Goldman-Rakic, 1991, 1994; Arnsten et al., 1994; Williams and Goldman-Rakic, 1995; Arnsten, 1997), nearly all evidence comes from working memory, rather than attentional, tasks.

\section{Summary}

The current study demonstrated that prenatal cocaine exposure produces enduring effects on the DA system underlying attention but does not alter DA systems underlying response initiation and selection. These lasting effects on DA activity may contribute to the changes in attention and arousal regulation reported in both animals and children exposed to cocaine in utero.

\section{REFERENCES}

Arnsten AFT (1997) Catecholamine regulation of the prefrontal cortex. J Psychopharmacol 11:151-162.

Arnsten AFT, Cai JX, Murphy BL, Goldman-Rakic PS (1994) Dopamine D-1 receptor mechanisms in the cognitive performance of young and aged monkeys. Psychopharmacology (Berl) 116:143-151.

Bayer LE, Kakumanu S, Mactutus CF, Booze RM, Strupp BJ (1996) Differential effect of idazoxan in rats exposed to cocaine prenatally and controls: evidence for the role of catecholamines in attentional function and dysfunction. Soc Neurosci Abstr 22:1858.

Bilitzke PJ, Church MW (1992) Prenatal cocaine and alcohol exposures affect rat behavior in a stress test (the Porsolt Swim Test). Neurotoxicol Teratol 14:359-364.

Booze RM, Lehner AF, Wallace DR, Welch MA, Mactutus CF (1997) Dose-response cocaine pharmacokinetics and metabolite profile following intravenous administration and arterial sampling in unanesthetized, freely moving male rats. Neurotoxicol Teratol 19:7-15.

Brown VJ, Robbins TW (1989a) Deficits in response space following unilateral striatal dopamine depletion in the rat. J Neurosci 9:983-989.

Brown VJ, Robbins TW (1989b) Elementary processes of response selection mediated by distinct regions of the striatum. J Neurosci 9:3760-3765

Brown VJ, Robbins TW (1991) Simple and choice reaction time performance following unilateral striatal dopamine depletion in the rat impaired motor readiness but preserved response preparation. Brain 114:513-526.
Bruckner JV, Jiang WD, Ho BT, Levy BM (1982) Histopathological evaluation of cocaine-induced skin lesions in the rat. J Cutan Pathol 9:83-95.

Carli M, Evenden JL, Robbins TW (1985) Depletion of unilateral striatal dopamine impairs initiation of contralateral actions and not sensory attention. Nature 313:679-682.

Carli M, Jones GH, Robbins TW (1989) Effects of unilateral dorsal and ventral striatal dopamine depletion on visual neglect in the rat: a neural and behavioral analysis. Neuroscience 29:309-328.

Carter CS, Mintun M, Nichols T, Cohen JD (1997) Anterior cingulate gyrus dysfunction and selective attention deficits in schizophrenia: (15O)H2O PET study during single-trial stroop task performance. Am J Psychiatry 154:1670-1675.

Church MW, Tilak JP (1996) Differential effects of prenatal cocaine and retinoic acid on activity level throughout day and night. Pharmacol Biochem Behav 55:595-605.

Coull JT (1998) Neural correlates of attention and arousal: insights from electrophysiology, functional neuroimaging and psychopharmacology. Prog Neurobiol 55:343-361.

DeBartolomeis A, Austin MC, Goodwin GA, Spear LP, Pickar D, Crawley JN (1994) Dopaminergic and peptidergic mRNA levels in juvenile rat brain after prenatal cocaine treatment. Mol Brain Res 21:321-332.

Dow-Edwards D, Mayes L, Spear L, Hurd Y (1999) Cocaine and development: clinical, behavioral, and neurobiological perspectives - a symposium report. Neurotoxicol Teratol 21:481-490.

Du W, Aloyo VJ, Pazdelski PS, Harvey JA (1999) Effects of prenatal cocaine exposure on amphetamine-induced dopamine release in the caudate nucleus of the adult rabbit. Brain Res 836:194-198.

Elsworth JD, Morrow BA, Mitra J, Roth RH (1999) Prenatal cocaine induces abnormal expression of the immediate-early gene Fos in ventral tegmental area dopamine neurons of the adult. Soc Neurosci Abstr 25:2080.

Evans SM, Cone EJ, Henningfield JE (1996) Arterial and venous cocaine plasma concentrations in humans: relationship to route of administration, cardiovascular effects and subjective effects. J Pharmacol Exp Ther 279:1345-1356.

Fischman MW, Schuster CR (1982) Cocaine self administration in humans. Fed Proc 41:241-246.

Friedman E, Yadin E, Wang HY (1996) Effect of prenatal cocaine on dopamine receptor-G protein coupling in mesocortical regions of the rabbit brain. Neuroscience 70:739-747.

Gabriel M, Taylor C (1998) Prenatal exposure to cocaine impairs neuronal coding of attention and discriminative learning. In: Annals of the New York Academy of Sciences, Vol 846, Cocaine: effects on the developing brain (Harvey JA, Kosofsky BE, eds), pp 194-212. New York: New York Academy of Sciences.

Garavan H, Morgan RE, Mactutus CF, Levitsky DA, Booze RM, Strupp BJ (2000) Impaired selective attention in rats exposed to cocaine prenatally: evidence from extra-dimensional shift and serial reversal tasks. Behav Neurosci 114:725-738.

Gerlach J, Hansen L (1993) Effect of chronic treatment with NNC756, a new D-1 receptor antagonist, or raclopride, a D-2 receptor antagonist, in drug-naïve Cebus monkeys: dystonia, dyskinesia and D-1-D-2 supersensitivity. J Psychopharmacol 7:355-364.

Goldstein LE, Murphy BL, Roth RH (1993) Effects of prenatal cocaine exposure on stress-induced behaviors. FASEB J 7:A856.

Goodwin GA, Bliven T, Kuhn C, Francis R, Spear LP (1997) Immediate early gene expression to examine neuronal activity following acute and chronic stressors in rat pups: examination of neurophysiological alterations underlying behavioral consequences of prenatal cocaine exposure. Physiol Behav 61:895-902.

Granon S, Passetti F, Thomas KL, Dalley JW, Barry J, Everitt BJ, Robbins TW (2000) Enhanced and impaired attentional performance after infusion of D1 dopaminergic receptor agents into rat prefrontal cortex. J Neurosci 20:1208-1215.

Horger BA, Roth RH (1996) The role of mesoprefrontal dopamine neurons in stress. Crit Rev Neurobiol 10:395-418.

Johns JM, Noonan LR (1995) Prenatal cocaine exposure affects social behavior in Sprague-Dawley rats. Neurotoxicol Teratol 17:569-576.

Kermadi I, Boussaoud D (1995) Role of the primate striatum in attention and sensorimotor processes: comparison with premotor cortex. NeuroReport 6:1177-1181.

Leech SL, Richardson GA, Goldschmidt L, Day NL (1999) Prenatal substance exposure: effects on attention and impulsivity of 6-year-olds. Neurotoxicol Teratol 21:109-118.

Leslie CA, Robertson MW, Jung AB, Liebermann J, Bennett Jr JP (1994) Effects of prenatal cocaine exposure upon postnatal development of neostriatal dopaminergic function. Synapse 17:211-215.

Levitt P, Harvey JA, Friedman E, Simansky K, Murphy EH (1997) New evidence for neurotransmitter influences on brain development. Trends Neurosci 20:269-274.

Lublin H, Gerlach J, Peacock L (1992) Effect of D1 and D2 agonists in primates withdrawn from long-term treatment with haloperidol: the potential role of dopamine D1 receptors in dyskinesia. Clin Neuropharmacol 15:448-458.

Lublin H, Gerlach J, Peacock L (1993) Chronic treatment with the D1 receptor antagonist, $\mathrm{SCH} 23390$, and the D2 receptor antagonist, racloprid, in cebus monkeys withdrawn from previous haloperidol treatment: 
extra pyramidal syndromes and dopaminergic supersensitivity. Psychopharmacology (Berl) 112:389-397.

Lublin H, Gerlach J, Morkeberg F (1994) Long-term treatment with low doses of the D1 antagonist raclopride in monkeys previously exposed to dopamine antagonists. Psychopharmacology (Berl) 114:495-504.

Mactutus CF (1999) Prenatal intravenous cocaine adversely affects attentional processing in preweanling rats. Neurotoxicol Teratol 21:539-550.

Mactutus CF, Herman AS, Booze RM (1994) Chronic intravenous mode for studies of drug (ab)use in the pregnant and/or group-housed rat: an initial study with cocaine. Neurotoxicol Teratol 16:183-191.

Mayes LC (1999) Developing brain and in utero cocaine exposure: effects on neural ontogeny. Dev Psychopathol 11:685-714.

Mayes LC, Grillon C, Granger R, Schottenfeld R (1998) Regulation of arousal and attention in preschool children exposed to cocaine prenatally. In: Annals of the New York Academy of Sciences, Vol 846, Cocaine: effects on the developing brain (Harvey JA, Kosofsky BE, eds), pp 126-143. New York: New York Academy of Sciences.

Molina VA, Wagner JM, Spear LP (1994) The behavioral response to stress is altered in adult rats exposed prenatally to cocaine. Physiol Behav 55:941-945.

Montgomery Jr EB, Buchholz SR (1991) The striatum and motor cortex in motor initiation and execution. Brain Res 549:222-229.

Morgan RE, Garavan H, Mactutus CF, Booze RM, Strupp BJ (1997) Prenatal cocaine exposure: enduring effects on sustained and selective attention. Neurotoxicol Teratol 19:249.

Murphy BL, Heffelfinger RN, Roth RH (1995) Rats exposed prenatally to cocaine show heightened FG 7142-induced deficits on a delayed alternation task. Soc Neurosci Abstr 21:707.

Murphy BL, Arnsten AFT, Jentsch JD, Roth RH (1996) Dopamine and spatial working memory in rats and monkeys: pharmacological reversal of stress-induced impairment. J Neurosci 16:7768-7775.

Pennington BF (1994) The working memory functions of the prefrontal cortices: implications for developmental and individual differences in cognition. In: The development of future oriented processes (Haith MM, Bensen JB, Roberts Jr RJ, Pennington BF, eds), pp 243-289. Chicago: University of Chicago.

Posner MI, Rothbart MK (1998) Attention, self-regulation and consciousness. Philos Trans R Soc Lond B Biol Sci 353:1915-1927.

Pullman SL, Watts RL, Juncos JL, Chase TN, Sanes JN (1988) Dopaminergic effects on simple and choice reaction time performance in Parkinson's disease. Neurology 38:249-254.

Richardson GA, Conroy ML, Day NL (1996) Prenatal cocaine exposure: effects on the development of school-age children. Neurotoxicol Teratol 18:627-634.

Robbins TW (1997) Arousal systems and attentional processes. Biol Psychol 45:57-71.

Robbins TW, Roberts AC, Owen AM, Sahakian BJ, Everitt BJ, Wilkinson L, Muir J, DeSalvia M, Tovee M (1994) Monoaminergic-dependent cognitive functions of the prefrontal cortex in monkey and man. In: Motor and cognitive functions of the prefrontal cortex (Thierry AM,
Glowinski J, Goldman-Rakic PS, Christen Y, eds), pp 93-111. Berlin: Springer.

Robinson SE, Enters EK, Jackson GF, Chinchilli VM, Maher JR, McDowell KP, Allen HM, Guo H (1994) Maternal and fetal brain and plasma levels of cocaine and benzoylecgonine after acute or chronic maternal intravenous administration of cocaine. J Pharmacol Exp Ther 271:1234-1239.

Romano AG, Harvey JA (1996) Prenatal exposure to cocaine disrupts discrimination learning in adult rabbits. Pharmacol Biochem Behav 53:617-621.

Sawaguchi T, Goldman-Rakic PS (1991) D1 dopamine receptors in prefrontal cortex involvement in working memory. Science 251:947-950.

Sawaguchi T, Goldman-Rakic PS (1994) The role of D1-dopamine receptor in working memory: local injections of dopamine antagonists into the prefrontal cortex of rhesus monkeys performing an oculomotor delayedresponse task. J Neurophysiol 71:515-528.

Thierry AM, Tassin JP, Blanc G, Glowinski J (1976) Selective activation of the mesocortical DA system by stress. Nature 263:242-244.

Wang HY, Runyan S, Yadin E, Friedman E (1995a) Prenatal exposure to cocaine selectively reduces D-1 dopamine receptor-mediated activation of striatal GS proteins. J Pharmacol Exp Ther 273:492-498.

Wang HY, Yeung JM, Friedman E (1995b) Prenatal cocaine exposure selectively reduces mesocortical dopamine release. J Pharmacol Exp Ther 273:1211-1215.

Wang XH, Levitt P, Jenkins AO, Murphy EH (1996) Normal development of tyrosine hydroxylase and serotonin immunoreactive fibers innervating anterior cingulate cortex and visual cortex in rabbits exposed prenatally to cocaine. Brain Res 715:221-224.

Watanabe M, Kodama T, Hikosaka K (1997) Increase of extracellular dopamine in primate prefrontal cortex during a working memory task. J Neurophysiol 78:2795-2798.

Wilkins AS, Genova LM, Posten W, Kosofsky BE (1998a) Transplacental cocaine exposure 1: a rodent model. Neurotoxicol Teratol 20:215-226.

Wilkins AS, Jones K, Kosofsky BE (1998b) Transplacental cocaine exposure 2: effects of cocaine dose and gestational timing. Neurotoxicol Teratol 20:227-238.

Williams GW, Goldman-Rakic PS (1995) Modulation of memory fields by dopamine D1 receptors in prefrontal cortex. Nature 376:572-575.

Wood RD, Molina VA, Wagner JM, Spear LP (1993) Prenatal exposure to cocaine alters later responsiveness to an uncontrollable stressor in periadolescent as well as adult rats. Soc Neurosci Abstr 19:1854

Wood RD, Bannoura MD, Johanson IB (1994) Prenatal cocaine exposure: effects of play behavior in the juvenile rat. Neurotoxicol Teratol 16:139-144.

Wood RD, Molina VA, Wagner JM, Spear LP (1995) Play behavior and stress responsivity in periadolescent offspring exposed prenatally to cocaine. Pharmacol Biochem Behav 52:367-374.

Zahrt J, Taylor JR, Mathew RG, Arnsten AFT (1997) Supranormal stimulation of D-1 dopamine receptors in the rodent prefrontal cortex impairs spatial working memory performance. J Neurosci 17:8528-8535. 